\title{
4
}

\section{The Absent Presence of Aeromobility: A Case of Australian Academic Air Travel Practices and University Policy}

\section{Andrew Glover, Tania Lewis, and Yolande Strengers}

\section{Introduction}

Over the past fifteen years, the mobilities paradigm has focused primarily on the movement of people and objects across space and time (Sheller \& Urry, 2006). It seeks to understand how these movements form patterns of travel, migration, transferal and pilgrimage. Thus, it focuses primarily on the movement itself, the destination to which various subjects and objects are moving to and what purpose this movement serves. These mobilities capture our attention, as an entity on the move is generally more interesting to an observer than one that is static. When something, or someone, is on the move, questions immediately arise: Where have they come from? Where are they going? Why are they going there?

A. Glover $(\bowtie) \bullet$ T. Lewis

RMIT University, Melbourne, VIC, Australia

e-mail: aglover@uow.edu.au; tania.lewis@rmit.edu.au

Y. Strengers

Monash University, Melbourne, VIC, Australia

e-mail: yolande.strengers@monash.edu 
Like many types of professionals working in the contemporary globalised economy, academics are increasingly 'on the move'. Those who travel to attend a conference in a far-flung destination are more likely to arouse interest than those who are sitting in an office. The image of a field-leading academic travelling across the world to give a keynote address at conferences is one that many academics aspire towards and a marker of success. Travel has become one of the primary ways in which academics demonstrate value to their peers and their institutions, by disseminating knowledge, in conference presentations and guest lectures. Travel also facilitates the acquisition of new knowledge, as interacting with those from other institutions and incorporating new ways of thinking into one's own research have become a highly normalised academic practice (Petersen, 2018).

Travel of this kind is an opportunity to develop (as well as a reflection of) 'network capital', now considered a highly prized commodity amongst academics, as well as professionals more broadly (Larsen et al., 2008). This refers to the extent to which an individual has connections with other academics, institutions and stakeholders, and is able to leverage those connections towards measures of success such as research collaborations, journal publications, high-quality books and research grants. These connections typically involve physical bodily co-presence, allowing academics to develop the necessary interpersonal relations and rapport that would support professional collaboration. Travel, particularly air travel for those who are more isolated in the Global South (Connell, 2007; Higham et al., 2019), is all but necessary to cultivating these simultaneously professional and personal relationships that are typical of successful academic endeavours (Urry, 2003; Storme et al., 2017).

Network capital, however, and the associated mobilities that it is constituted by, are not evenly distributed. Mobilities and hypermobilities for certain individuals and groups create 'immobilities' for others (Hannam et al., 2006). What is more, there is often a relationship between the two. That is, in order for certain individuals and groups to be mobile, others tend to be rendered immobile. In academia, immobilities are seen in those without sufficient research funding to travel, in those whose teaching obligations coincide with conference dates, in those with parenting or caring responsibilities or in those whose geographical remoteness makes 
international travel unfeasible. Immobility also undergirds academic mobility in the domestic sphere, as partners — some of whom may also be academics — often stay behind to care for family and other dependents.

Following Elliott and Urry (2010), we are interested in how professional academic 'mobile lives' are undergirded by other 'immobile lives'. The hypermobile academic, a mode being encouraged and celebrated within contemporary and neoliberal academia_particularly in Australia and the Global North-is embedded in an array of relatively hidden practices and structures of support that generate often hidden inequities. We are also interested in how the hypermobile academic archetype, which is widely aspired to, is in direct conflict with the commitments to environmental sustainability that many universities (and academics themselves) hold. University sustainability policies appear to have been 'immobilised' when it comes to considerations of the environmental consequences of air travel for climate change. Is it that these policies are not taken seriously, or have other policies — which tend to encourage academics to fly-rendered them less visible, and therefore more absent from discussions about the sustainability of academic life?

We explore such questions through the concept of absent present mobilities, where certain aspects of mobility are foregrounded and central to our attention (i.e. present), whilst others are obscured, marginalised and remain somewhat hidden (i.e. absent). We propose the term absent presence, as a way of exploring the hidden dimensions, immobilities or absences that are generated by the overt presence and focus on academic air travel.

The chapter draws on our research on academic air travel and virtual collaboration in Australian universities to develop the concept of absent present mobilities and uncover some of its effects on environmental sustainability and equity. In the following sections, we explore how academic experiences of air travel illustrate absent presence in three domains. First, we discuss the inequities raised by academics who are present globally, whilst others-be they family members and dependents, or less mobile academics - remain at home. Second, we draw on an analysis of Australian university strategic plans and internationalisation policies to reveal how these institutional ambitions mean regular air travel by academics and other people associated with the sector. We show how 
aeromobility also has an absent presence in these policy orientations, frequently assumed rather than explicitly articulated. Third, we draw on past analysis of Australian universities' sustainability policies, where air travel is largely absent within the heightened contemporary presence of sustainability. Finally, we discuss what the concept of absent present mobilities might offer researchers in the future, as a way to confront inequalities in mobility and the potential for alternative scholarship.

\section{Conceptual Framework}

The concept of absent presence is not restricted to policies relating to mobility and has been deployed in a number of ways elsewhere. In discussing the phenomenon of race in public discourse in Europe, M'charek et al. characterise absent presence as 'something that oscillates between reality and nonreality, which appears on the surface and then hides underground' (2014, p. 459). Here, absent presence is conceptualised as a dynamic, alternating between distinct phases of prominence at certain times, and obscurity at others. Absent presence has also been used in discussions of household consumption. In a discussion of disposal and waste, Hetherington (2004, p. 159) argues that waste often retains a trace semiotic presence in the home, despite it being made materially absent. In this case, absent presence refers to the lingering effect of objects moved from one space to another, where their presence can be felt even after they are physically removed.

In the realm of social interaction, it has been argued that people's use of mobile information technology devices creates the 'challenge of absent presence' (Geyer \& Zacarias-Farah, 2003). While one may be physically present with other people, Geyer argues that mobile phones create a 'diverted or divided consciousness', because the primary focus of attention is to the stimuli provided by the device rather than those in their immediate surroundings: 'We are present but simultaneously rendered absent; we have been erased by an absent presence' (ibid., p. 227).

Each of these uses of the term absent presence highlights how it has conceptualised different aspects of social life. In the most general sense, we use the term 'absent presence' to illustrate our contention that social 
phenomena have aspects that are easily observed because they are central to discourse and practice, as well as aspects that are more hidden and require reflection and research to uncover. For something to be considered absent, it may be marginalised, in the sense that it is deliberately considered peripheral and unimportant in common discourse and practice. Absences may also be overlooked or forgotten in a non-deliberate manner. In this case, the concept of absent presence may draw attention to previously unexamined contradictions and injustices that exist in social life- the so-called elephant in the room.

There are also other arenas where there are competing assumptions about the nature of academic life in policies that govern contemporary universities. For instance, Royston et al. (2018) argue that energy demand policy in higher education is largely 'invisible', meaning that the practices for which energy is used, and might increase or decrease energy consumption, are dictated primarily by policies whose focus is elsewhere. For instance, policies that seek to improve the student experience by allowing the library to remain open for 24 hours have significant energy implications (lighting, heating) without explicitly claiming to do so. Likewise for policies that seek to grow the university, as this growth and the additional infrastructures and services that this growth entails, tend to involve the creation of new demand for energy use within an institution. In other words, mobility and energy demands can be seemingly absent in university policies whilst having an obvious and immediate presence in the dayto-day practices of academics and university life.

The absent-presence dualism we develop in this paper captures Goffman's (1959) front-stage/back-stage distinction. Famously describing social life as performance, Goffman argued that there are both public and private aspects to the self. The public audience generally only sees the 'front stage' activity, whilst the private 'back-stage' remains hidden from view. In the case of academic aeromobility, the front stage can be seen as the academic who attends and is 'present' at international and national conferences, and whose presentation of self thereby conforms to expectations of academic mobility and success. 'Back-stage', however, are those whose groundedness enables such forms of hypermobility to occur: family, dependents and sustainability policies that do not confront the environmental impact of flying. 
The concept of absent presence can also be considered in terms of normativity. Describing social relations in terms of their relative mobilities and immobilities can highlight the unequal power relations they are constituted by, providing a justification for more evenly distributed mobility (Hannam et al., 2006, p. 15). In applying to certain phenomena, we argue that which is absent should, for reasons of sustainability, equity, diversity or simply consistency, be made more present. We conceptualise absent presence as a means to address and redress forms of inequality and marginalisation that are unjustified, regardless of whom or what this applies to. In the context of the mobilities paradigm, we hope to draw attention to instances where dichotomies of mobility and immobility are reflective of unsustainability, inequity, homogeneity or inconsistency within the academy and university sector.

In this vein, absent presence can also be conceptualised through the discourse of 'hidden labour' (Crain et al., 2016). In the case of academia, hidden labour is the internal service roles that-while necessary to the functioning of academic departments — are generally uncompensated and which are unlikely to be considered as valued academic output. Examples of academic service roles are faculty governance, faculty recruitment, evaluation and promotion, internal awards, student admissions and scholarships and so on. Academic women tend to perform a significantly higher proportion of this work, which can be considered labour that is generally hidden from the view of academic performance metrics and scholarly outputs (Guarino \& Borden, 2017). It can be said, then, that hidden labour has an absent presence in academic life: absent from the scholarly metrics that often dictate an academic candidacy for employment or promotion, whilst having a (necessary) presence in the day-to-day functioning of the academic departments. Likewise, some academics — who are more likely to be male-may have a significant presence in their field through promotion and hypermobility, whilst being more absent from the academic service roles they are otherwise obliged to fulfil.

As a concept for the mobilities literature on air travel, absent presence seeks to examine that which often gets overlooked in the academic practice of flying. This is not to say that mobilities scholars have completely overlooked what gets left behind when the focus is on that which is most present. Gustafson (2014) and Bergström (2010) highlight the stresses 
and impacts that frequent business travel has on travellers who are away from home frequently. Likewise, researchers of business travel have described the tensions between work and life commitments (Espino et al., 2002; Black \& Jamieson, 2007). The experience of jet lag is also one that could be characterised as absent presence, with travellers being expected to perform professional obligations despite temporal and geographical dislocation (Anderson, 2015). However, we seek to operationalise this concept of 'absence' further, highlighting how various absences and presences act simultaneously to mediate mobility itself. It is not merely that these absent presences have unfortunate side effects, as is the case with jet lag, that could potentially be overcome through technological innovation. The very practice of academic air travel is enabled and constituted by the various forms of absent presence that we discuss here. The goal of this chapter then involves understanding what types of 'absences' manifest in practices and policies of academics and contemporary universities.

\section{Methods}

In the first analysis section of this paper, entitled 'Mobile Academics', we draw on two data sources. The first is an online survey $(N=301)$ of Australian-based academics about their experiences and views of workrelated air travel and their use of non-flying alternatives. Respondents were recruited through a combination of social media (Twitter, Facebook), emails to disciplinary associations, and through institutional emails and newsletters. The survey was designed and hosted on the Qualtrics platform in 2015 and took approximately 15-20 minutes to complete. Quantitative responses were analysed in Qualtrics. Upon completing the survey, respondents could nominate themselves to be interviewed on similar topics in more depth. This series of in-depth, semi-structured qualitative interviews with 24 Australian academics forms the second source of data for this section. These interviews were conducted in 2015 and 2016 over Skype, phone and in-person, and generally took between 40 minutes and one and a half hours. Interviews were recorded and transcribed using a professional transcription service, then coded and analysed in NVIVO qualitative analysis software. These interviews went into 
more depth from the survey questions, discussing academics' air travel practices, their views regarding the importance of air travel to their careers, and their use of non-flying alternatives. Both data sources include participants from a range of disciplines, stages of career progression, workload (full time, part-time, or casual) and proportions of teaching or research.

In the second section of the paper, entitled 'Absent Presence in University Internationalisation', we draw on data from a qualitative textual analysis of the strategic plans and internationalisation policies of a sample of fourteen Australian universities. This sample included city and regional campuses in different states and territories, as well as universities both within and outside the prestigious 'Group of Eight' (a network of older, larger, research-intensive) academic institutions. This approach ensured we did not overly focus on any particular type of university that was more or less concerned with internationalisation than was typical for the sector. These documents were coded thematically and analysed to understand how academic air travel was understood in the context of these university policies and plans. We describe the key policy areas in which academic travel has a clear presence in the assumptions made about academics flying, but are absent from explicit articulation.

In the third section, entitled 'Absent Presence of Sustainable Air Travel Policy', we draw on research published elsewhere where we analysed sustainability policies of all 43 Australian universities that sought to understand the extent to which air travel is acknowledged as a source of carbon emissions and environmental impact (Glover et al., 2017). We did this by reviewing university websites and their various policies and strategies that relate to sustainability, searching for material related to air travel, business travel, flying, carbon emissions and so on. Relevant content was downloaded and coded in NVIVO according to any references that were made to academic air travel. On the basis of these policies and online documents we then categorised each of the universities into one of three categories: 'air travel ignorers', 'recognition without intervention' and 'air travel substituters'. We briefly discuss examples from this analysis, insofar as it illustrates the concept of absent presence, in the relevant section. 


\section{Mobile Academics}

The demand for physical presence abroad entails an absence from home life, both professionally, in terms of being away from one's home institution, and personally, in terms of being away from family, dependants and friends. In this section, we discuss how the prominence of academic mobility practices entails corresponding absences that the demands of professional life often obscure. Understanding the ambiguities and disconnects between academic work life and home life brings the true costs of air travel to the fore, allowing us to understand what enables academic mobilities 'behind the scenes'.

One of the most common reasons for Australian academics to undertake air travel is to attend conferences. When asked what the primary reasons are for undertaking work-related air travel, 92 per cent of Australian academics indicated that they flew to attend conferences, symposia and workshops. Meetings with other academics were the next most common reason for flying (56 per cent of respondents), followed by undertaking fieldwork or data collection (37 per cent), meetings with industry partners ( 25 per cent), attending industry events (13 per cent), other (14 per cent), and commuting ( 2 per cent) and only 1 per cent indicating that they do not fly. Given these responses, we can conclude that conferencing and meeting are the primary reasons why academics fly. While other forms of air travel can clearly form part of academic practice in particular fields, these appear to be the most relevant for academia as a whole. More importantly, for this paper, they are the parts of academic life that highlight the specific occasions of mobile presence in the academic career.

Conferences and smaller events such as symposia and workshops are one of the primary forums in which academics can develop and maintain a presence in their field. For early-career academics, conference attendance affords the opportunity to gain exposure for themselves and their work, thereby making themselves more widely known to prospective employers. For more established academics, conferences are often seen as a way to develop and maintain professional networks, as well as staying up to date on current research developments in their field. The data from 
our survey indicated that frequent air travel, and the opportunities for presence that it provides, are associated with academic seniority and career success-however, this association is contested elsewhere (Wynes et al., 2019). In our study, of those academics that took over eight domestic return flights in the past twelve months, 64 per cent of this group of respondents hold Associate Professor or Professor positions at their institutions. This speaks to the roles that physical presence plays in academic networking and knowledge creation, as those who are able to afford to travel to meet with others are likely to progress in their career in a way that more immobile academics do not.

This ability to build and maintain networks for collaboration was highlighted in an interview with Aaron, a full-time Associate Professor in Computing and Information Systems based in Wollongong, who recalled his itinerary for the past twelve months, six months of which was on study leave. The first three months of the year were 'normal work', which nevertheless involved several conferences. In April he travelled to a conference in Amsterdam, primarily for its educational value, followed by a flagship conference in New York, primarily to meet people. In September he delivered a keynote presentation in Bangkok, then another keynote in Nanjing in October. Finally, he travelled to Texas in December for an information systems conference, where he did not attend the main conference event, but where his presence was required at committee meetings and for consultation work. While this may not be a common academic flying profile, it nevertheless points to the role that air travel plays in facilitating Australian research that is internationally focused, or which has a globalised industry associated with it. Air travel of this kind is constitutive of the highly internationalised orientations of many Australian universities, and the research networks that they seek a presence in. The role of this academic's physical body is central to this expectation-that his body being physically present at the events, as opposed to attending via a video conference, is currently seen as a requisite part of presenting and networking practices.

However, this increasingly normalised practice of flight-enabled academic mobility is not embraced by academics across the board. When asked whether they would like to undertake more or less work-related air travel, 35 per cent of our survey respondents indicated they would like to undertake more, 52 per cent were satisfied with the amount they 
currently undertake and 13 per cent would like to undertake less. Of those academics who indicated they would like to fly more, they typically cited the opportunities for career progression and intellectual fulfilment that attending remote events and meetings in person brought. Of those academics who indicated that they would like to undertake less workrelated air travel, the two overwhelmingly most common reasons were due to its environmental impact and the impact on their home and family life. These reasons were also common for those who were satisfied with the amount of air travel they do, often citing a conflict between the benefits to one's academic career on the one hand, and the effect of being absent from one's home and the environmental impact on the other.

Within all these views about the opportunities that networking brings, is the assumption that having a presence at these events, and in order to engage and participate in these events effectively, one must be physically and bodily present. While academics events are slowly starting to become digitised, such as by broadcasting a live stream of events online, it is still widely assumed that the only way to 'be there' is to be there physically. Presenting one's work physically through the body is how academics conventionally present much of their work. However, conferencing mobilities of this kind are largely reliant on corresponding immobilities that make such travel possible and desirable.

This was clearly evident in our interview with Sarah, a single mother academic with two children aged 10 and 16 . She regularly travelled interstate and throughout the Pacific region, managing and implementing education and capacity-building projects, as well as invitations to specific events. For each work trip she takes she has to make care arrangements for her children, either with their father, from whom she is separated, or with a house sitter at the cost of $\$ 50$ a day. Sarah describes these difficulties arranging 'home life' for the time she is away:

So there was a bit of a hiccup in the family life the other day that has put the suggestion that the children may not stay at their dad's for the whole six weeks and so I'm still trying to work that out ... by chatting to them online, on Facebook and all that sort of stuff. I'm trying to think 'Oh my God, what other options have I got?' So, it does have an impact. (Sarah, Associate Professor, Research \& Teaching, Full Time, Education, Regional NSW) 
Sarah's case highlights how, in the practice of academic conference travel, there is a hidden and highly gendered domestic labour associated with academic mobility. The infinitely mobile researcher tends to be premised upon a masculinist model of academic labour and 'presence' in the academic world. Babies and child care are often absent or not taken into account at conferences; although occasionally child care will be provided at academic events, and foreground the absent-present dichotomy. Expectations of and by academics to travel abroad assume that others will remain at home to care for family and dependents while they are away. By limiting the likelihood of those who cannot fly to succeed in academia, the normalisation of air travel presents a potential reinforcer of existing inequities within the academic community. So long as mobilities remain absent from discussions about academic inclusion, less-mobile groups are likely to remain more absent from academia more than others. This immobility may be due to a range of reasons, such as air travel being incompatible with caring responsibilities, personal illness or health concerns, inadequate funding, or ethical objections to flying.

An increasingly common form of absent present mobilities can be seen in concerns about the environmental impact of academics' (often frequent) flying. Sally, an interview informant, describes how she has difficulty in explicitly acknowledging the environmental impact of her work-related air travel:

I feel like I can't really. There's a lot of things I can do in my life like not using plastic bags and things, the air travel is necessary for me to do my job properly so I don't feel like it's in the category of things that I can worry too much about in terms of my agency to do, to make good choices, yeah, and when I did the questionnaire I was feeling very guilty about it. (Research Fellow, Full Time, Research, Communications studies, Melbourne)

This illustrates how concerns about the environmental impacts of air travel can be made absent in the consciousness of environmentally aware academics, despite air travel's obvious presence in common understandings of the successful academic career. Air travel's impact appears to have been rendered largely absent from explicit acknowledgement, as performing the role of the mobile academic compels Sally to fly to fulfil her work 
obligations. Here, absent presence manifests itself in the tension between striving to progress in one's chosen career, often accompanied by a desire to improve the state of the world, whilst reckoning with an excessive carbon footprint (Higham et al., 2014).

This section has shown how the mobilities and immobilities of academic air travel highlight the absent-presence dichotomy. From the survey data, we can see how air travel has a strong presence in the careers of highly successful academics. However, as the testimonies of Sarah and Sally show, this presence obscures the more hidden aspect of air travel, be it the difficulties of those academics with caring responsibilities or the environmental concerns about excessive flying. In the next section, we move on from academic practice to understand how absent presences manifest in university policies with regard to air travel.

\section{Absent Presence in University Internationalisation}

Mobilities can be conceptualised not merely in the actual movement of people, objects and information, but in the forms of organisation that assume and encourage such movements. For instance, institutional policies may deal with these mobilities explicitly, such as through travel policies that specify professional obligations whilst travelling. However, mobilities can also be implicit in policies that seek to direct institutions to operate in particular ways. Certain institutional orientations can have the effect of creating practices that are more mobile than they might otherwise be, or creating entirely new practices where mobility is necessary to their performance. We argue that these latter policies are mobilities characterised by another form of absent presence. Recognising the embedded mobility in these policies requires a 'reading between the lines' approach, where references to movement may not be immediately obvious but nevertheless have a presence in their application. Understanding how these policies play out in practice is necessary to see where absent present mobilities exist. 
We find these absent presences in Australian university's strategic plans and internationalisation policies with regard to air travel. These plans articulate how the broad strategic objectives of the Australian universities are to become increasingly internationalised and global in their reach and impact. This includes ambitions for institutions to be global in their reach and impact, by conducting research abroad and disseminating new knowledge at national and international events. For instance, the University of Canberra states an objective to 'increase the proportion of publications co-authored with international collaborators' (University of Canberra, 2013, p. 6), where such collaborations tend to involve physical co-presence facilitated by air travel. The plans also often include objectives to recruit academics from a global pool of potential applicants, fulfilling ambitions to be globally renowned institutions. For instance, the University of Adelaide aims to attract 'high citations researchers who count amongst the top $1 \%$ in the world in their fields' (University of Adelaide, 2012, p. 12). Finally, it includes strategies to recruit and teach international students as well as Australian students, as evidenced by the number of Australian universities establishing international campuses in Asia, Europe and the Middle East (Lane, 2011). Each of these areas entails a vast amount of air travel by academic staff and students in increasingly internationalised Australian universities.

Absent from these strategic plans and internationalisation policies, however, is what implications this will have on academic life and day-today practice. Air travel is embedded in many of the core assumptions about the increased internationalisation of the university, without being explicitly acknowledged as such. Increasing international impact, collaboration with international colleagues and pursuing international sources of funding for research all assume that academics will be flying to the necessary meetings and conferences where these endeavours are cultivated and pursued; the previous interview informant Aaron being a prime example of this. As such, academic air travel has an absent presence in these policies - rarely, if ever, being acknowledged as the primary form of mobility that is and will be required to actualise the vision of an increasingly internationalised university.

The aeromobility that is implied, but rarely articulated explicitly, in these plans, speaks to the normalisation of air travel in everyday 
consciousness, including that of policymakers. Air travel has come to be an expected and somewhat routinised part of academic life as a means to attend conferences, symposia, meetings and conducting fieldwork-all of which are necessary elements to fulfil the internationalisation strategies. The absence of air travel in these university strategies and policies, then, speaks to its sheer presence in the daily lives of academics. It appears that air travel is a thoroughly expected facet of academic life, and as such, is not even acknowledged as the central means by which academics will implement a highly mobile institutional orientation. This absent presence of mobility is particularly important, given that the primary form of mobility assumed - that of air travel — has particularly significant implications for sustainability. Unsurprisingly, many university sustainability policies also fail to acknowledge air travel in any substantial way-an issue we discuss in the following section.

\section{Absent Presence in University Sustainability Policy}

Another guiding ambition of many Australian universities is sustainability. Many universities have signed the Talloires Declaration, indicating a commitment to the values of environmental sustainability for their whole institution (Talloires Declaration Institutional Signatory List, 2016). This involves commitments to reducing the institution's environmental footprint, through initiatives such as energy and water efficiency in buildings, resource recovery and waste prevention, and lower carbon emissions in transport. University buildings are often subject to sustainability construction methods and retrofits to ensure they do not waste energy and water in their operation. Most universities encourage commuting practices that are less energy-intensive, such as public transport, bicycling and car-pooling, where appropriate. With much sustainability research taking place at universities, it is unsurprising that these institutions are generally progressive in embracing sustainability principles and practices-particularly in Australia. 
In research we have previously published, we found that over half ( 22 out of 43) of the universities could be classified as 'ignorers', as they did not acknowledge the sustainability implications of air travel. This included universities that had no sustainability plan at all, as well as those that did have sustainability plans, initiatives or reporting, but that did not include air travel. A further 13 universities did recognise air travel as a sustainability issue but did not describe any concrete means by which they would seek to reduce its impact on their overall environmental footprint. Typically, this involved stating generalised ambitions to reduce the carbon emissions from flying or simply naming it as a source of these emissions. Only six universities described ways in which their air travel emissions could be reduced by flying less. These overwhelmingly focused on substituting air travel with digital 'alternatives' such as video conferencing. However, as mobilities scholars (Faulconbridge et al., 2009; Haynes, 2010; Storme et al., 2017; Jones et al., 2018) have found, video conferencing and other forms of digital communication tend to supplement rather than substitute for air travel. Overall, we concluded that the Australian university system lacks a comprehensive recognition and strategy for reducing air travel emissions.

This general lack of engagement with the environmental implications of air travel is also indicative of an absent presence in these university sustainability policies. Given air travel's intensity as a carbon-emitting activity, it should be highly prominent in these policies. The environmental impact of flying arguably justifies it having a central presence in university sustainability planning, alongside the impact of other policies around university buildings and transport provisioning. However, our analysis revealed these policies were completely absent of comprehensive measures to reduce air travel, and often absent of any acknowledgement of its impact at all. One could argue that this absence from sustainability policy speaks to the centrality of air travel in the contemporary higher education sector. As we have discussed in the previous sections, the strategic objectives of universities have been formulated with an assumption that academics will engage in regular air travel. Sustainability policies, then, appear to be incapable of seriously challenging these assumptions, because they would challenge many of the fundamental goals of the contemporary university. 
Absences of explicit acknowledgement of air travel can also be seen in university health and workplace safety policy. Health policy for university employees tends to assume that these people will be located on or near campus, not flying internationally. Therefore, the physical demands of (particularly) international travel around fatigue and jet lag are generally unacknowledged. This speaks to the place that air travel has in other university policies we have discussed-an assumed, hidden and seemingly absent role rather than the normalised and prominent role it often plays in the practices of academics themselves.

\section{Conclusion}

This paper has identified how mobility can be understood as having an absence-presence dualism; on the one hand, with aspects that are easily observed and foregrounded in academic practice and policy, and, on the other hand, with those that are less obvious. This absent presence concept captures many of the inequities and unsustainabilities of contemporary academia. As we have discussed, certain forms of mobility may appear marginal in certain contexts, such as university internationalisation policy and strategic plans, whilst being absolutely central in practice. Likewise, academics who have a presence at events such as conferences and workshops are idealised and rewarded in academia, whilst the immobilities and support structures that enable them are largely absent from recognition. Drawing attention to these absent presences moves mobilities scholarship towards a critical politics of presence, giving a more nuanced understanding of how aeromobility is positioned within the broader academic work-life ecology.

How do issues that should be of central concern, such as carbon emissions from air travel or inequities in access to flying, come to have an absent presence in academic practice and policy? Has the normalisation of work-related air travel in everyday life, and its integration with tourism and other recreational travel, contributed to this? It seems likely that there is something about the specific materiality and spatiality of air travel itself that makes it easier to render absent in our everyday discussions. Unlike, for example, car dependency, which is foregrounded so clearly in 
the minds of the residents of congested city dwellers (Bissell \& Fuller, 2017), air travel is relatively obscured from view most of the time for most people. The obvious sensory impact of air travel is restricted to airports and their proximate suburbs, where aircraft noise is more prominent. Disruptions to the aviation network are rarely noticed by those who are not flying at the time. It seems possible that this relative absence from everyday perception, and particularly from perception when located on a university campus, has allowed air travel to evade scrutiny as an intensely high carbon-emitting activity to which academics have become highly reliant on.

In contrast, it may also be that the pleasures and benefits that air travel affords - the exploration of new places, meetings and reunions with colleagues abroad, an 'escape' from daily work and home routines-actually mean that many of us have an interest in maintaining and perpetuating air travel 'entitlements'. In this case, many academics and university administrators may prefer to have air travel remain absent from everyday consciousness and policy, even if they are working specifically on issues that relate to climate change and sustainability.

Regardless of how accurate these speculations are, this paper has demonstrated the need for an increased understanding of the different types of absent presences in mobilities scholarship, in the context of both the university sector and elsewhere. In this respect, this work could provide a basis for greater critical examination of how certain forms of presence are privileged over others, and how certain absences are made possible in the context of imperatives that demand their presence. Critical reflection is needed about the practices and policies that constitute and reinforce meanings of academic success and how these both enable and require particular forms of mobility and immobility.

The demand for physical presence at academic events normalises air travel in the academic career, making career progression more difficult for those who cannot fly as readily, or at all. This is especially the case for geographically remote academics located in Australia and the Global South (Glover et al., 2019; Higham et al., 2019), where international travel to the Global North generally requires long periods of time away from home. The archetypal conference-hopping academic is arguably hypermobile, male and free of any caring obligations or domestic duties 
that might keep them 'grounded' at home. Consequently, one could argue that the demand for air travel in academia tends to disadvantage women generally, and particularly those women with primary caring obligations, since it is they who more often take these duties on compared to their male partners (Suitor et al., 2001). With this expectation for mobility at all stages of the academic career becoming so normalised, irrespective of the life circumstances of academics themselves, air travel is yet another dimension whereby gendered inequities are reproduced in academic life.

In drawing attention to the absent presence of mobilities in contemporary academic practice, we are simultaneously highlighting other salient characteristics of the culture within the profession. Academia's current model is arguable premised on long hours, and on a thorough blurring of home life and work. Air travel is emblematic of this blurring, as tourism and business travel may be combined on the same journeys, and 'travel time' is also often 'work time', as academics become increasingly capable of working on the move with mobile devices and ubiquitous data connections.

In describing mobilities as being at once absent and present, the potential for alternative forms of academic practice also comes into view. Just as we have asked what gets left absent when certain forms of presence are normalised, we might also ask what alternative forms of academic practice are possible, given the absent presence duality. What other forms of academia might be 'left behind'? Slow academia (Hartman \& Darab, 2012) is one such formulation, which seeks to address questions of ethical academic labour in an increasingly individualised, neoliberal academic culture. Slower academia, in contrast to the hypermobile, globally expansive form of academia facilitated by air travel, may focus more closely on the local community. Collaboration may be emphasised more highly than competition. Domestic labour and care, so often marginalised and made absent in contemporary understandings of academic success, would be integrated into academic culture. As we have alluded to in previous sections, we believe this may go some way to addressing the inequities in who is more likely to succeed in the academic career.

Finally, the 2020 COVID-19 pandemic has-at least temporarilyshifted academic air travel practices significantly, grounding most 
academics for extended periods of time. Travel budgets were impacted due to the financial precarity of many institutions, and many conferences and other academic events shifted into a more virtual form. The domestic spaces that travelling academics often left behind were made more present, as academics worked, presented and interacted from home. While academic mobility does appear to be on the increase by the end of 2020, it is unclear what trajectory academic air travel will take in the future. Will academia's culture of air travel return to pre-pandemic levels or has the pandemic shifted practices in more durable ways?

From concerns about climate change to work-life balance to gender inequity, we can see how different types of absent presences manifest themselves in different parts of academic life. We argue that, in drawing attention to the concept of absent presence itself, mobilities studies will be better equipped to recognise them in other settings. Each instance of absent presence will likely be context dependant, requiring different strategies to respond to the specific forms of inequity or unsustainability they describe. Most importantly, though, it will encourage us to look beyond what is most apparent in any given social context, promoting a more critical and curious form of mobilities scholarship.

\section{References}

Anderson, J. (2015). Exploring the consequences of mobility: Reclaiming jet lag as the state of travel disorientation. Mobilities, 10(1), 1-16. https://doi.org/1 0.1080/17450101.2013.806392

Bergström, G. (2010). Consequences of overnight work travel for personal social relations: Problems, promises, and further repercussions. Mobilities, 5(3), 369-386. https://doi.org/10.1080/17450101.2010.494841

Bissell, D., \& Fuller, G. (2017). Material politics of images: Visualising future transport infrastructures. Environment and Planning A, 49(11), 2477-2496. https://doi.org/10.1177/0308518X17727538

Black, I., \& Jamieson, S. (2007). Up, up and fading away: The work and family life of executive international travellers. Policy and Practice in Health and Safety, 5(2), 63-78. https://doi.org/10.1080/14774003.2007.11667694

Connell, R. (2007). Southern theory. Allen \& Unwin. 
Crain, M., Poster, W., \& Cherry, M. (2016). Invisible labor: Hidden work in the contemporary world. University of California Press.

Elliott, A., \& Urry, J. (2010). Mobile lives. Routledge.

Espino, C. M., Sundstrom, S. M., Frick, H. L., Jacobs, M., \& Peters, M. (2002). International business travel: Impact on families and travellers. Occupational and Environmental Medicine, 59(5), 309-322. https://doi.org/10.1136/ oem.59.5.309

Faulconbridge, J. R., Beaverstock, J. V., Derudder, B., \& Witlox, F. (2009). Corporate ecologies of business travel in professional service firms. European Urban and Regional Studies, 16(3), 295-308. https://doi. org/10.1177/0969776409104694

Geyer-Allely, E., \& Zacarias-Farah, A. (2003). Policies and instruments for promoting sustainable household consumption. Journal of Cleaner Production, 11(8), 923-926.

Glover, A., Strengers, Y., \& Lewis, T. (2017). The unsustainability of academic aeromobility in Australian universities. Sustainability: Science, Practice and Policy, 13(1), 1-12. https://doi.org/10.1080/15487733.2017.1388620

Glover, A., Lewis, T., \& Strengers, Y. (2019). Overcoming remoteness: The necessity of air travel in Australian universities. Australian Geographer, 1-19. https://doi.org/10.1080/00049182.2019.1682319

Goffman, E. (1959). The presentation of self in everyday life. Doubleday.

Guarino, C. M., \& Borden, V. M. H. (2017). Faculty service loads and gender: Are women taking care of the academic family? Research in Higher Education, 58(6), 672-694. https://doi.org/10.1007/s11162-017-9454-2

Gustafson, P. (2014). Business travel from the traveller's perspective: Stress, stimulation and normalization. Mobilities, 9(1), 63-83. https://doi.org/1 $0.1080 / 17450101.2013 .784539$

Hannam, K., Sheller, M., \& Urry, J. (2006). Editorial: Mobilities, immobilities and moorings. Mobilities, 1(1), 1-22. https://doi.org/10.1080/ 17450100500489189

Hartman, Y., \& Darab, S. (2012). A call for slow scholarship: A case study on the intensification of academic life and its implications for pedagogy. Review of Education, Pedagogy, and Cultural Studies, 34(1-2), 49-60. https://doi. org/10.1080/10714413.2012.643740

Haynes, P. (2010). Information and communication technology and international business travel: Mobility allies? Mobilities, 5(4), 547-564. https://doi. org/10.1080/17450101.2010.510337 
Hetherington, K. (2004). Secondhandedness: Consumption, disposal, and absent presence. Environment and Planning D: Society and Space, 22(1), 157-173. https://doi.org/10.1068/d315t

Higham, J. E. S., Cohen, S. A., \& Cavaliere, C. T. (2014). Climate change, discretionary air travel, and the 'flyers' dilemma. Journal of Travel Research, 53(4), 462-475. https://doi.org/10.1177/0047287513500393

Higham, J. E. S., Hopkins, D., \& Orchiston, C. (2019). The work-sociology of academic aeromobility at remote institutions. Mobilities, 14(5), 1-20. https:// doi.org/10.1080/17450101.2019.1589727

Jones, I., Faulconbridge, J., Marsden, G., \& Anable, J. (2018). Demanding business travel: The evolution of thetimespaces of business practice. In Demanding Energy (pp. 257-277). Springer International Publishing. https:// doi.org/10.1007/978-3-319-61991-0_12

Lane, J. E. (2011). Importing private higher education: International branch campuses. Journal of Comparative Policy Analysis: Research and Practice, 13(4), 367-381. https://doi.org/10.1080/13876988.2011.583106

Larsen, J., Urry, J., \& Axhausen, K. (2008). Coordinating face-to-face meetings in mobile network societies. Information, Communication \& Society, 11(5), 640-658. https://doi.org/10.1080/13691180802126752

M'charek, A., Schramm, K., \& Skinner, D. (2014). Technologies of belonging: The absent presence of race in Europe. Technology, \& Human Values, 39(4), 459-467. https://doi.org/10.1177/0162243914531149

Petersen, A. M. (2018). Multiscale impact of researcher mobility. Journal of The Royal Society Interface, 15(146), 20180580. https://doi.org/10.1098/ rsif.2018.0580

Royston, S., Selby, J., \& Shove, E. (2018). Invisible energy policies: A new agenda for energy demand reduction. Energy Policy, 123, 127-135. https:// doi.org/10.1016/j.enpol.2018.08.052

Sheller, M., \& Urry, J. (2006). The new mobilities paradigm. Environment and Planning A, 38(2), 207-226. https://doi.org/10.1068/a37268

Storme, T., Faulconbridge, J. R., Beaverstock, J. V., Derudder, B., \& Witlox, F. (2017). Mobility and professional networks in academia: An exploration of the obligations of presence. Mobilities, 12(3), 405-424. https://doi.org/1 $0.1080 / 17450101.2015 .1116884$

Strengers, Y. (2015). Meeting in the global workplace: Air travel, telepresence and the body. Mobilities, 10(4), 592-608. https://doi.org/10.1080/1745010 1.2014 .902655 
Suitor, J. J., Mecom, D., \& Feld, I. S. (2001). Gender, household labor, and scholarly productivity among university professors. Gender Issues, 19(4), 50-67. https://doi.org/10.1007/s12147-001-1007-4

Talloires Declaration Institutional Signatory List. (2016). http://www.ulsf.org/ programs_talloires_signatories.html\#Australia

University of Adelaide. (2012). Beacon of enlightenment: Strategic plan 2013-2023 (p. 17). Accessed 27 July 2017. https://www.adelaide.edu.au/ $\mathrm{VCO} /$ beacon/beacon-of-enlightenment.pdf.

University of Canberra. (2013). Breakthrough: Strategic plan 2013-17. Accessed 27 July 2017. https://www.canberra.edu.au/about-uc/strategic-plan/documents/break-through-uc-strategic-plan-prospectus-2013-17.PDF.

Urry, J. (2003). Social networks, travel and talk. British Journal of Sociology, 54(2), 155-175.

Wynes, S., Donner, S. D., Tannason, S., \& Nabors, N. (2019). Academic air travel has limited influence on professional success. Journal of Cleaner Production, 226, 959-967. https://doi.org/10.1016/j.jclepro.2019.04.109

Open Access This chapter is licensed under the terms of the Creative Commons Attribution 4.0 International License (http://creativecommons.org/licenses/ by/4.0/), which permits use, sharing, adaptation, distribution and reproduction in any medium or format, as long as you give appropriate credit to the original author(s) and the source, provide a link to the Creative Commons licence and indicate if changes were made.

The images or other third party material in this chapter are included in the chapter's Creative Commons licence, unless indicated otherwise in a credit line to the material. If material is not included in the chapter's Creative Commons licence and your intended use is not permitted by statutory regulation or exceeds the permitted use, you will need to obtain permission directly from the copyright holder.

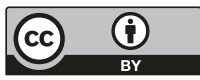

